\title{
ОПТИМИЗАЦИЯ ЛОГИСТИЧЕСКОЙ СИСТЕМЫ МАЛОГО ТОРГОВОГО ПРЕДПРИЯТИЯ
}

\author{
N.A. Tod, T.S. Shumkova \\ THE OPTIMIZATION OF LOGISTIC SYSTEM \\ OF SMALL TRADING COMPANY
}

Показана актуальность оптимизационных мероприятий в области логистики для мальх торговых предприятий, которые работают в условиях высокой конкуренции. В качестве объекта исследования выступает малое торговое предприятие, занимающееся продажей продуктов питания. Был проведен анализ звенъев логистической системы анализируемого предприятия в разрезе логистических функций: области закупок, поставок, складирования и грузопереработки, сбыта. Приведен перечень логистических затрат, возникающих в каждой области. Перечислены показатели для оценки эффективности логистической системы предприятия также в разрезе данных областей. Проведен анализ внешней среды предприятия, которую составляют поставщики, подрядчики, покупатели, государство и органы власти, а такюе конкуренты. Приведена калькуляция общих затрат предприятия до проведения мероприятий. В качестве интегрального показателя эфФективности логистической деятельности предприятия выбран показатель доходности собственного капитала (ROE), в основе расчета которого лежит модель Дюпона. Приведен алгоритм расчета и произведены расчеты данного показателя для первоначального состояния предприятия. С целью анализа текущего положения компании был проведен анализ точки безубыточности компании. На основании результатов проведенного анализа были предложены мероприятия по оптимизации логистической деятельности. На основании данных о результатах внедрения был произведен пересчет показателей ROE и точки безубыточности предприятия после проведения мероприятий и произведена оценка эффективности предложенных мероприятий. Предложенные мероприятия позволили: увеличить оборот компании на $10 \%$; обеспечить резерв безубыточности в размере 24818 ед. товара, или 6 353,3 тыс. руб.; при увеличении объема продаж на 10 \% обеспечить рост прибыли предприятия со 125 тыс. руб. до 193 тыс. руб.; увеличить показатель маржи чистой прибыли на о,22 \%; увеличить показатель ROA с 5 до $7 \%$, показатель $R O E$ - с 41 до $57 \%$.

Ключевъе слова: малое торговое предприятие, логистическая система, оптимизация, логистические операщии и функции, логистические затраты, показатели эффективности, точка безубыточности, доходность активов, доходность собственного капитала. 
The relevance of optimizing actions in the field of logistics for small trade enterprises working in the conditions of high competition was shown. A small trade enterprise engaged in the sale of food acted as the object of the research. The analysis of links of logistic system of analyzed enterprise in the section of logistic functions was carried out: the areas of purchases, deliveries, warehousings and cargo handlings and sale. The list of logistic expenses arising in each area was provided. The indicators for the assessment of the efficiency of logistic system of the enterprise also in the section of these areas were listed. The analysis of the environment of the enterprise which was made by the suppliers, contractors, buyers, the state and authorities, and also competitors was also carried out. The accounting of general expenses of the enterprise before carrying out actions was given. As an integrated indicator of the efficiency of logistic activity of the enterprise the indicator of profitability of its own capital (ROE) of which calculation Dupont's model was chosen as the cornerstone. The algorithm of calculation was given and calculations of this indicator for initial condition of the enterprise were made. In order to analyze the current position of the company an analysis of the break-even point of the company was also carried out. On the basis of the results of the analysis the actions for optimization of logistic activity were offered. On the basis of the implementation the data of the results, $R O E$ indicator and breakeven points of the enterprise were recalculated after the measures were carried out and the effectiveness of the proposed measures was evaluated. The proposed measures allowed increasing the turnover of the company by $10 \%$; providing break-even reserve in the amount of 24818 units of goods or 6353.3 thousand rubles; if the volume of sales increased by $10 \%$, the growth of profit of the enterprise from 125 thousand rubles to 193 thousand rubles would be ensured; net margin would increase by $0.22 \%$; ROA would increase from 5 to $7 \%$ and $R O E$ from 41 to $57 \%$.

Keywords: small trading company, logistics system, optimization, logistics operations and functions, logistics costs, performance indicators, break-even point, return on assets, return on equity.

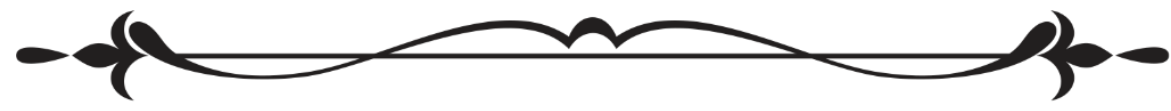

В условиях высокой конкуренции на рынке малые предприятия торговой сферы, особенно занимающиеся реализацией продуктов питания, нуждаются в оптимизационных мероприятиях, позволяющих улучшить показатели эффективности их деятельности и тем самым повысить свои конкурентные преимущества. Применение логистических технологий и методологии логистики как раз направлено на оптимизацию всех ресурсов предприятия любого размера.

В качестве объекта исследования выступает малое торговое предприятие. Предметом исследования является оптимизация логистической системы анализируемого предприятия. 


\section{Социально-экономический и әуманитарный журнал Красноярского ГАУ. 2020. №1}

Целью данного исследования является разработка мероприятий по оптимизации логистической системы анализируемого предприятия. Для достижения поставленной цели был проведен детальный анализ логистической системы предприятия, произведен расчет основных показателей эффективности деятельности предприятия, предложены оптимизационные мероприятия и оценен эффект от их реализации.

Деятельность анализируемого предприятия включает оптовую и розничную торговлю продуктами, а именно: мясом и мясом птицы, консервами из мяса и мяса птицы; рыбой, ракообразными и моллюсками, консервами и пресервами из рыбы и морепродуктов; замороженными пищевыми продуктами.

Проведем анализ звеньев логистической системы анализируемого предприятия. Внешнюю среду предприятия составляют поставщики, подрядчики, покупатели, государство и органы власти, а также конкуренты.

Поставщиками предприятия являются: местные производители свежего мяса, мясных деликатесов и свежего мяса птицы, а также оптовые торговые компании, осуществляющие поставки замороженной рыбы, морепродуктов, консервов, пресервов, замороженных пищевых продуктов.

Ввиду специфики работы организации, она имеет обширный круг конкурентов: к ним относятся торговые точки на рынке в непосредственной близости к торговым точкам анализируемого предприятия, а также крупные розничные сети («Командор», «Красный Яр», «Окей», «Лента»и т. п.).

Проведенный анализ показал, что конечными потребителями предприятия являются физические лица: ведущие совместное домохозяйство; проживающие в г. Красноярске; среднемесячный доход которых на одного члена семьи составляет 15 ооо-20 ооо руб.; посещающие продуктовый магазин в среднем один-два раза в неделю; средний размер покупки которых в среднем составляет 2000 руб.

Государство и органы власти задают законодательные основы деятельности анализируемой организации, осуществляют лицензирование деятельности, а также сбор налоговых, лицензионных платежей.

Движение материального потока происходит по прямой схеме.

Далее рассмотрим логистические функции и операции на предприятии.

Анализируемое предприятие является предприятием розничной торговли, осуществляющим продажу через собственную торговую точку. Логистическое администрирование ввиду небольшого размера организации осуществляет директор. Он осуществляет планирование, организацию логистической деятельности и управление ею. В штате сотрудников предприятия выделена отдельная должность, отвечающая за организацию поставок на предприятие. 
В области закупок осуществляются следующие логистические операции:

- определение размера заказа;

- предоставление информации о требованиях к продукции;

- определение бюджета на закупку продукции;

- поиск и выбор поставщиков (предполагает возникновение затрат на оформление и размещение заказов на продукцию);

- ведение переговоров с поставщиками, заключение договоров на поставку продукции;

- согласование условий договора поставки с учетом специальных организационных, технологических и других требований покупателя.

В области поставок продукции осуществляются следующие логистические операции:

- диспетчеризация материальных потоков и транспорта;

- определение расписания поставок продукции;

- контроль качества поставляемой продукции;

- согласование и выполнение расчетов с поставщиками;

- транспортно-экспедиционные операции;

- доставка продукции до склада.

После закупки товаров и их поставки в организацию товары проходят стадию хранения на складе предприятия и дальнейшую реализацию. Обе эти логистические функции осуществляются непосредственно в торговой точке.

Складирование и грузопереработка продукции на складе предполагает осуществление следующих процессов:

- подготовка складского помещения к приему продукции;

- обслуживание и обеспечение работы складского оборудования;

- погрузочно-разгрузочные работы;

- приемка продукции по количеству и качеству;

- хранение продукции;

- соблюдение условий хранения, проведение профилактических мероприятий, предупреждающих порчу продукции;

- формирование запаса продукции;

- комплектация и подготовка продукции к реализации;

- cбор, хранение и возврат тары поставщикам. ты [5]:

Данные логистические операции предполагают следующие затра-

- затраты на складирование поступающих материалов, промежуточное складирование, складирование готовой продукции, на сбор, хранение и передачу данных о запасах, на эксплуатацию вычислительной техники, регистрацию поступающих заказов, управление запасами, объединение заказов на различные номенклатурные позиции в один заказ; 


\section{Социально-экономический и әуманитарный журнал Красноярского ГАУ. 2020. №1}

- затраты на получение, внутрискладское перемещение, размещение, хранение, грузопереработку, сортировку, разукрупнение, комплектацию продукции и ее упаковку;

- затраты, связанные с оплатой за оборотные средства в запасах и основные фонды складов;

- расходы по содержанию и эксплуатации складов и оборудования;

- расходы по операциям с тарой и упаковкой;

- заработная плата складского персонала.

Функция сбыта товара предполагает следующие операции:

- передачу товаров конечным потребителям и получение оплаты;

- оказание сервиса;

- проверку количества и качества товара;

- удаление отходов и утилизацию.

Затраты, относящиеся к функции сбыта [4]:

- транзакционные затраты (затраты на поиск покупателей);

- эксплуатационные затраты по упаковке;

- затраты на удаление отходов и утилизацию;

- затраты на оказание сервиса;

- затраты владения (с точки зрения покупателя, это сумма затрат на приобретение, эксплуатацию, техническое обслуживание и послепродажное обслуживание).

Калькуляцию затрат предприятия представим в таблице 1.

Таблица 1

\section{Калькуляция затрат предприятия}

\begin{tabular}{|c|c|}
\hline Показатель & $\begin{array}{c}\text { Значение } \\
\text { показателя, руб. }\end{array}$ \\
\hline 1 & 2 \\
\hline Затраты, относимые на себестоимость продукции, всего & 21786000 \\
\hline В т. ч. переменные, всего: & 20926250 \\
\hline стоимость приобретения товара у поставщиков & 19658625 \\
\hline $\begin{array}{l}\text { заработная плата продавцов и работника склада с начисле- } \\
\text { ниями }\end{array}$ & 1036488 \\
\hline транспортные расходы & 231137 \\
\hline В т. ч. постоянные, всего: & 859750 \\
\hline услуги охраны & 120000 \\
\hline часть заработной платы директора с начислениями & 180423 \\
\hline $\begin{array}{l}\text { часть заработной платы сотрудника, отвечающего за органи- } \\
\text { зацию поставок на предприятие с начислениями }\end{array}$ & 139327 \\
\hline аренда торговой площади & 420000 \\
\hline Затраты, относимые предприятие в целом & 490000 \\
\hline В т. ч. переменные, всего: & 117149 \\
\hline транспортные расходы & 117149 \\
\hline В т. ч. постоянные, всего: & 372851 \\
\hline часть заработной платы директора с начисл & 120282 \\
\hline
\end{tabular}




\begin{tabular}{|l|c|}
\hline \multicolumn{1}{|c|}{ Окончанце табл. 1} \\
\hline \multicolumn{1}{|c|}{$\mathbf{1}$} & 2 \\
\hline $\begin{array}{l}\text { часть заработной платы сотрудника, отвечающего за органи- } \\
\text { зацию поставок на предприятие с начислениями }\end{array}$ & 92885 \\
\hline коммунальные услуги & 59684 \\
\hline услуги связи & 51000 \\
\hline расходы на рекламу & 49 о0о \\
\hline подоходные налоги & 66 о0о \\
\hline Постоянные, всего & 66 о0о \\
\hline В т. ч. ЕНВД & 66 о0о \\
\hline Итого & 22342 о0о \\
\hline
\end{tabular}

Для оценки эффективности логистической системы предприятия могут быть использованы различные показатели [1]:

1) Эффективность логистического администрирования:

- выработка на одного работника;

- трудоемкость;

- уровень квалификации персонала и др.

2) Эффективность закупок продукции:

- оптимальный размер закупки;

- объем закупаемой продукции;

- периодичность размещения заказов;

- срок исполнения заказа;

- количество поставщиков;

- затраты на закупку и др.

3) Эффективность процесса поставки продукции:

- время поставки;

- частота поставки;

- безотказность поставки;

- интервал поставки и др.

4) Эффективность складирования и грузопереработки:

- время хранения;

- количество поступлений на склад;

- запасы в пути;

- уровень механизации складских работ;

- коэффициент оборачиваемости продукции на складе;

- коэффициент использования площади склада;

- затраты на складирование и хранение и др.

5) Эффективность сбыта:

- объем реализованной продукции;

- скорость товарооборота;

- товарооборачиваемость;

- количество потребителей;

- коэффициент реализации и др. 


\section{Социально-экономический и әуманитарный журнал Красноярского ГАУ. 2020. №1}

Одним из комплексных показателей оценки эффективности деятельности логистической системы является показатель ROE - доходность собственного капитала (доходность к чистой стоимости компании), расчет которого лежит в основе модели оценки эффективности деятельности фирмы Дюпона [3].

Схема расчета данного показателя в ходе анализа текущего состояния предприятия представлена на рисунке 1 (значения показателей даны в тыс. руб.).

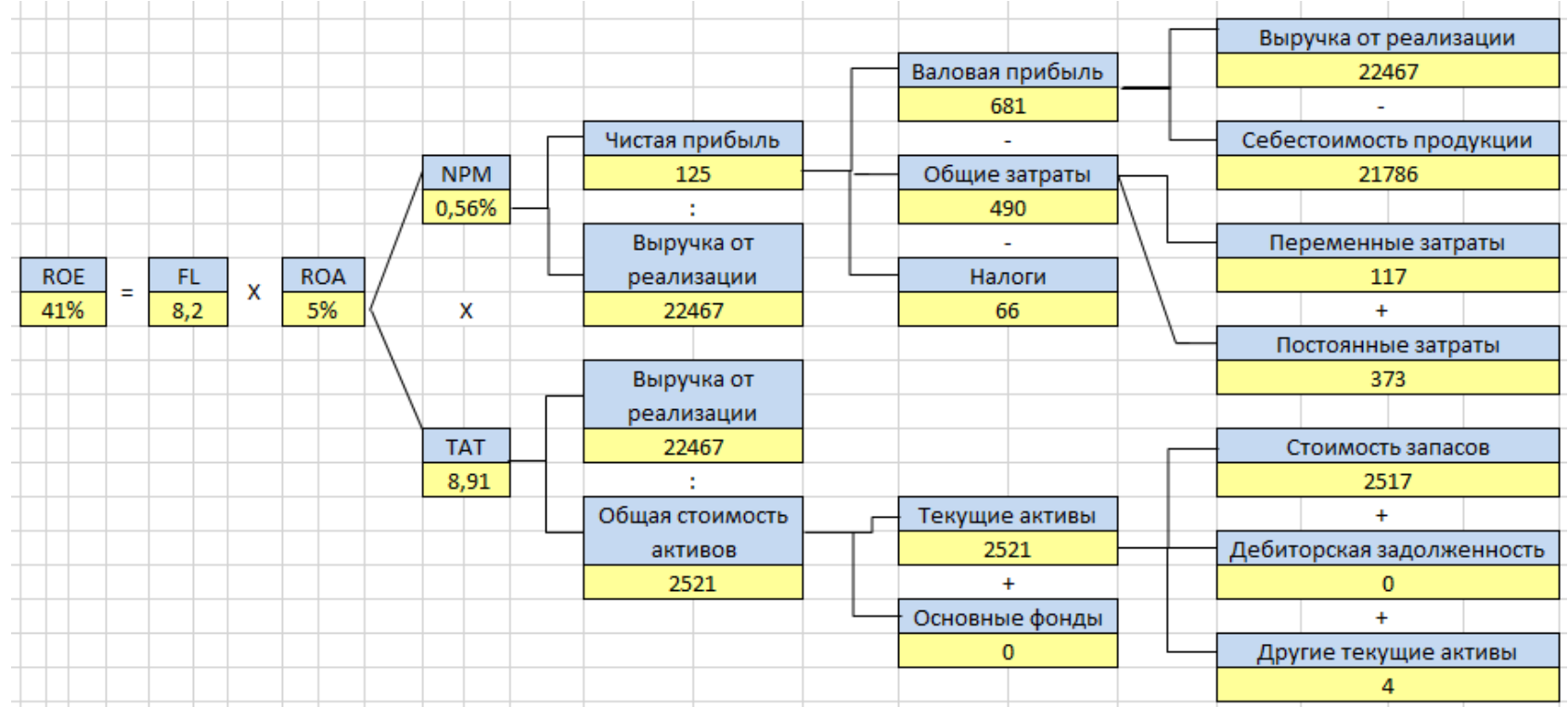

Рис. 1. Определение доходности собственного капитала

Полученное значение финансового рычага (FL) говорит о высокой зависимости от политики контрагентов и соответственно - повышенном риске деятельности предприятия. Собственный капитал составляет лишь 10,9 \% общей стоимости активов предприятия.

Маржа чистой прибыли (NPM) предприятия составляет лишь 0,56 \%, что связано со спецификой и локализацией деятельности предприятия оно занимается розничной торговлей продуктовыми товарами на рынке и не может устанавливать высокую торговую наценку, уровень конкуренции слишком высок. Прибыль предприятия формируется в основном за счет обеспечения стабильного большого оборота торговли. Подтверждает данный вывод также достаточно высокий уровень оборачиваемости активов: так как активы предприятия полностью сформированы запасами, то увеличение размеров выручки происходит в основном за счет увеличения торгового оборота. Доходность активов (ROA), или коэффициент доходности предприятия, показывает, что реальный уровень дохода компании по отношению к авансированным средствам и их элементам, а также к общему объему текущих затрат составляет 5 \%. Пока- 
затель доходности к чистой стоимости компании (ROE) демонстрирует высокие значения за счет небольшой величины собственного капитала предприятия.

С целью анализа текущего положения компании также был проведен анализ точки безубыточности компании [2]. Исходные данные и алгоритм расчета представлены в таблице 2.

\section{Расчет точки безубыточности}

\begin{tabular}{|c|c|}
\hline Показатель & $\begin{array}{c}\text { Значение } \\
\text { показателя }\end{array}$ \\
\hline 1. Объем реализации товаров, ед. & 87762 \\
\hline 2. Средняя цена 1 единицы, руб. & 256 \\
\hline 3. Выручка, руб. & 22467000 \\
\hline \multicolumn{2}{|l|}{ Переменные затраты } \\
\hline 4. Средняя закупочная цена 1 единицы, руб. & 224 \\
\hline $\begin{array}{l}\text { 5. Заработная плата продавцов и работника склада } \\
\text { с начислениями, руб. }\end{array}$ & 1036488 \\
\hline 6. Транспортные расходы, руб. & 348286 \\
\hline 7. Переменные затраты, всего, руб. & 21043399 \\
\hline \multicolumn{2}{|l|}{ Постоянные затраты } \\
\hline 8. Аренда торговой площади, руб. & 420000 \\
\hline 9. Заработная плата директора с начислениями, руб. & 300705 \\
\hline $\begin{array}{l}\text { 10. Заработная плата сотрудника, отвечающего за органи- } \\
\text { зацию поставок на предприятие с начислениями, руб. }\end{array}$ & 232212 \\
\hline 11. Услуги охраны, руб. & 120000 \\
\hline 12. Коммунальные услуги, руб. & 59684 \\
\hline 13. Услуги связи, руб. & 51000 \\
\hline 14. Расходы на рекламу, руб. & 49000 \\
\hline 15. ЕНВД, руб. & 66000 \\
\hline 16. Итого постоянных затрат, руб. & 1298601 \\
\hline \multicolumn{2}{|l|}{ Показатели для расчета точки безубыточности } \\
\hline 17. Маржинальный доход, руб. (стр. 3 - стр.7) & 1423601 \\
\hline 18. Прибыль на единицу товара, руб. (стр. 17/ стр.1) & 16 \\
\hline 19. Переменные затраты на единицу товара, руб. (стр. 7/ стр.1) & 240 \\
\hline 20. Коэффициент маржинального дохода (стр. 17/ стр. 3) & 0,063 \\
\hline 21. Точка безубыточности, руб. (стр. 16/ стр. 20) & 20494274 \\
\hline
\end{tabular}

График точки безубыточности фирмы отражен на рисунке 2. 


\section{Социально-экономический и әуманитарный журнал Красноярского ГАУ. 2020. №1}

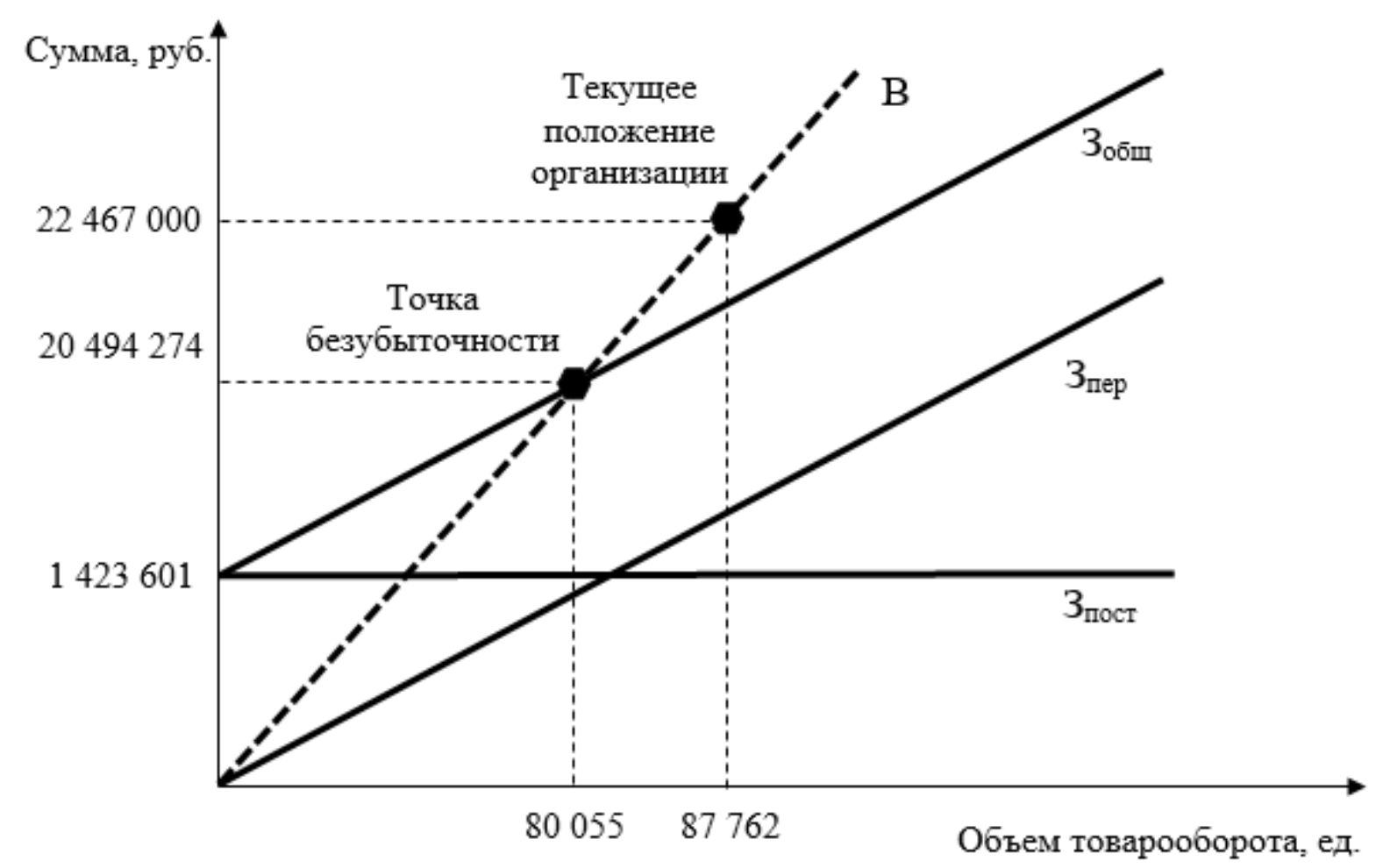

Рис. 2. Текущее положение анализируемого предприятия относительно точки безубыточности

По результатам анализа деятельность предприятия прибыльна, резерв безубыточности составляет 87762 - 80 о55 = 7706 ед. товара, или 8,8 \% от общего объема товарооборота. В денежном выражении резерв безубыточности составляет 1972726 руб. Для более устойчивого конкурентного положения фирмы на рынке необходимо изыскать резервы увеличения прибыли за счет снижения логистических издержек.

Исходя из проведенного анализа, было предложено снижение транспортных расходов за счет применения аутсорсинга. Но это привело к неизбежному увеличению размера заказа. Увеличение размера закупаемой партии обуславливает необходимость расширения складской площади. Однако это влечет увеличение расходов на коммунальные услуги, аренду помещения, охрану и т. д. В части решения данной проблемы было предложено использование ближайшего к торговой точке хранилища (распределительного центра), расходы на которое включают лишь аренду бокса. Такое мероприятие позволило увеличить торговую площадь в имеющейся в распоряжении торговой точке и расширить ассортимент продаваемой продукции.

В качестве компании, осуществляющей перевозки, было важно выбрать фирму, специализирующуюся на перевозках пищевых продуктов. Средняя цена за перевозку 5 т продукции по городу Красноярску составляет 7 ооо руб.

Объем продаж в момент оценки текущего положения составлял 12 т в месяц. Предлагаемые мероприятия позволили увеличить объем 
продаж на 10 \%. Таким образом, объем продаж составил 13,2 т в месяц или 1584 т в год. При перевозке грузовиками, вмещающими 5 т продукции, понадобилось около 32 рейсов в год. Средняя стоимость рейса составляет 7 тыс. руб., т. е. сумма годовых расходов составила 224000 руб.

Аренда складского бокса составила 60 ооо руб/год.

Выручка предприятия увеличилась пропорционально увеличению объемов реализации - приблизительно на $10 \%$.

Пересчет точки безубыточности после проведения предложенных мероприятий представлен в таблице 3.

Таблица 3

Расчет точки безубыточности после проведения мероприятий

\begin{tabular}{|c|c|}
\hline Показатель & $\begin{array}{c}\text { 3начение } \\
\text { показателя }\end{array}$ \\
\hline 1. Объем реализации товаров, ед. & 96538 \\
\hline 2. Средняя цена 1 единицы, руб. & 256 \\
\hline 3. Выручка, руб. & 24713700 \\
\hline \multicolumn{2}{|l|}{ Переменные затраты } \\
\hline 4. Средняя закупочная цена 1 единицы, руб. & 224 \\
\hline $\begin{array}{l}\text { 5. Заработная плата продавцов и работника склада с начис- } \\
\text { лениями, руб. }\end{array}$ & 1036488 \\
\hline 6. Транспортные расходы, руб. & 224000 \\
\hline 7. Переменные затраты, всего, руб. & 22884976 \\
\hline \multicolumn{2}{|l|}{ Постоянные затраты } \\
\hline 8. Аренда торговой и складской площадей, руб. & 480000 \\
\hline 9. Заработная плата директора с начислениями, руб. & 300705 \\
\hline $\begin{array}{l}\text { 10. Заработная плата сотрудника, отвечающего за органи- } \\
\text { зацию поставок на предприятие с начислениями, руб. }\end{array}$ & 232212 \\
\hline 11. Услуги охраны, руб. & 120000 \\
\hline 12. Коммунальные услуги, руб. & 59684 \\
\hline 13. Услуги связи, руб. & 51000 \\
\hline 14. Расходы на рекламу, руб. & 49000 \\
\hline 15. ЕНВД, руб. & 66000 \\
\hline 16. Итого постоянных затрат, руб. & 1358601 \\
\hline \multicolumn{2}{|l|}{ Показатели для расчета точки безубыточности } \\
\hline 17. Маржинальный доход, руб. (стр. 3 - стр. 7) & 1828725 \\
\hline 18. Прибыль на единицу товара, руб. (стр. 17/ стр. 1) & 19 \\
\hline 19. Переменные затраты на единицу товара, руб. (стр. 7/ стр.1) & 237 \\
\hline 20. Коэффициент маржинального дохода (стр. 17/ стр. 3) & 0,074 \\
\hline 21. Точка безубыточности, руб. (стр. 16/ стр. 20) & 18360369 \\
\hline
\end{tabular}

График положения фирмы относительно точки безубыточности после проведения мероприятий отразим на рисунке 3. 


\section{Социально-экономический и гуманитарный журнал Красноярского ГАУ. 2о2о. №1}

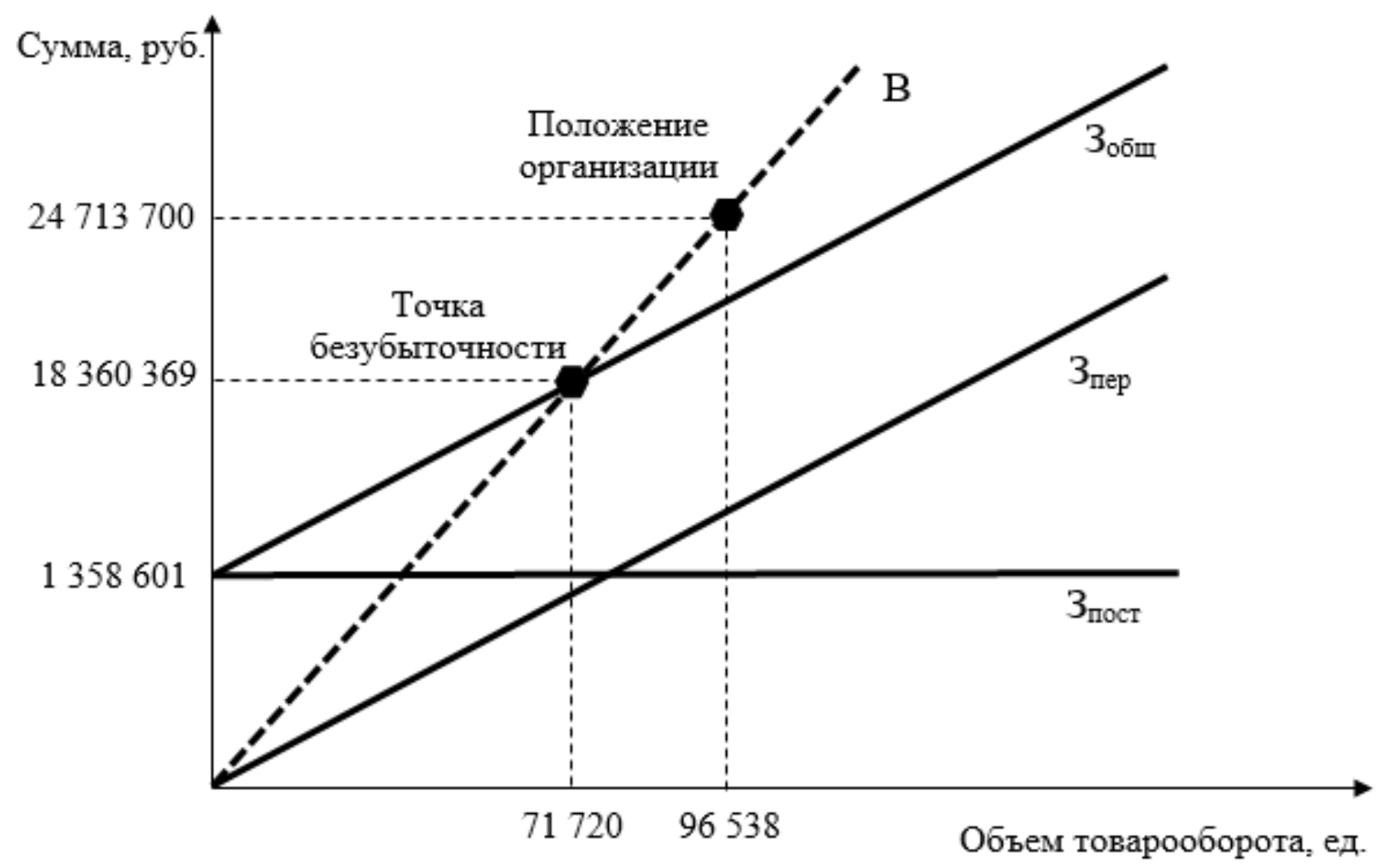

Рис. 3. Положение анализируемого предприятия относительно точки безубыточности после проведения мероприятий

Пересчет показателя ROE после проведения мероприятий представлен на рисунке 4.

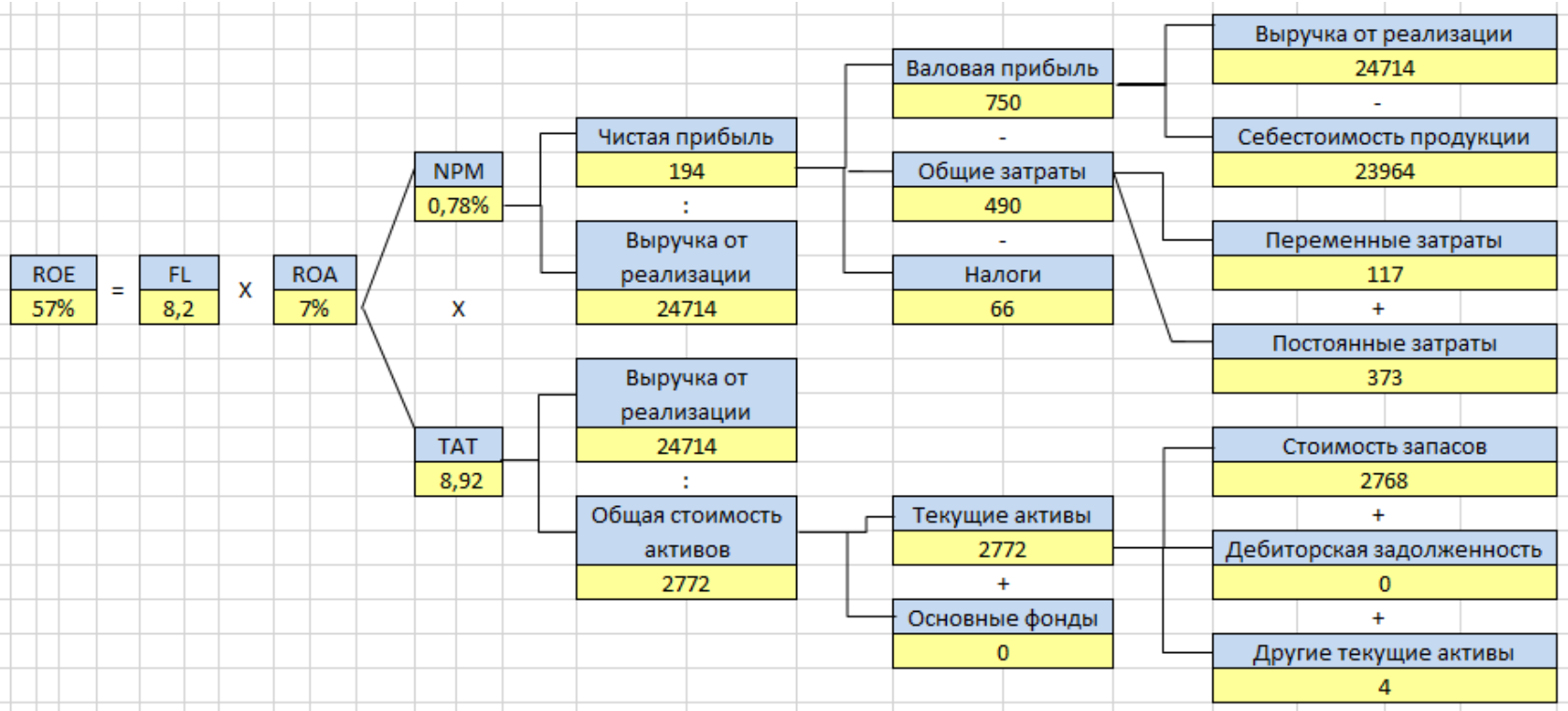

Рис. 4. Определение доходности собственного капитала после проведения мероприятий 
Полученный коэффициент ROE выше коэффициента за предыдущий год на 16 \%, что говорит о положительном эффекте проведенных мероприятий. Таким образом, предлагаемые мероприятия позволили улучшить показатели предприятия посредством наращения объемов оборота торговли.

Таким образом, реализация предложенных мероприятий позволила:

- увеличить оборот компании на $10 \%$;

- снизить уровень точки безубыточности в товарном и денежном выражении на 10,4 \%;

- обеспечить резерв безубыточности в размере $96538-71720=$ $=24818$ ед. товара или 24 713,7 - 18 360,4 = 6 353,3 тыс. руб.;

- при увеличении объема продаж на 10 \% обеспечить рост прибыли предприятия со 125 тыс. руб. до 193 тыс. руб.;

- увеличить показатель маржи чистой прибыли на 0,22 \%;

- увеличить итоговые показатели эффективности логистической системы предприятия: доходность активов (ROA) - с 5 до $7 \%$, доходность к чистой стоимости компании (ROE) - c 41 до $57 \%$.

$\mathrm{B}$ целях снижения расходов были предложены мероприятия по замещению части логистических функций предприятия услугами сторонних фирм, а именно - снижение расходов на транспортировку за счет аутсорсинга, изменение размера закупаемой партии, аренда складского бокса. Данные меры привели к увеличению объемов реализации за счет увеличения торговой площади, а, следовательно, к увеличению выручки, прибыли, снижению точки безубыточности и увеличению показателя эффективности логистической деятельности.

\section{Литература}

1. Лукиных В.Ф., Тод Н.А. Логистика: учеб. пособие / Краснояр. гос. аграр. ун-т. Красноярск, 2018. 352 с.

2. Моськина Ю.Д., Ларионова Н.П. Методы и рекомендации по определению безубыточности предприятия в различных областях хозяйственной деятельности // Экономика, социология и право. М.: Ин-т стратегических исследований, 2017. - С. 15-19.

3. Тод Н.A., Мишагин P.A., Стецун E.A. Обоснование целесообразности формирования распределенной сети консолидационных логистических центров в АПК региона // Логистика - Евразийский мост: мат-лы XIV Междунар. науч.-практ. конф. / Краснояр. гос. аграр. ун-т. Красноярск, 2019. С. 320-325.

4. Формирование рыночных структур в сфере обращения. URL: https://www.bibliofond.ru/view.aspx?id=456345\#8.

5. Эффективность логистики: анализ издержек и контроль за ними // Библиотека управления. URL: https://www.cfin.ru/management/ manufact/cost.shtml. 


\section{Literatura}

1. Lukinyh V.F., Tod N.A. Logistika: ucheb. posobie / Krasnojar. gos. agrar. un-t. Krasnojarsk, 2018. 352 s.

2. Mos'kina Ju.D., Larionova N.P. Metody i rekomendacii po opredeleniju bezubytochnosti predprijatija $\mathrm{v}$ razlichnyh oblastjah hozjajstvennoj dejatel'nosti // Jekonomika, sociologija i pravo. M.: In-t strategicheskih issledovanij, 2017. - S. 15-19.

3. Tod N.A., Mishagin R.A., Stecun E.A. Obosnovanie celesoobraznosti formirovanija raspredelennoj seti konsolidacionnyh logisticheskih centrov v APK regiona // Logistika - Evrazijskij most: mat-ly XIV Mezhdunar. nauch.-prakt. konf. / Krasnojar. gos. agrar. un-t. Krasnojarsk, 2019. S. 320-325.

4. Formirovanie rynochnyh struktur $\mathrm{v}$ sfere obrashhenija. URL: https://www.bibliofond.ru/view.aspx?id $=456345 \# 8$.

5. Jeffektivnost' logistiki: analiz izderzhek i kontrol' za nimi // Biblioteka upravlenija. URL: https://www.cfin.ru/management/manufact/cost.shtml.

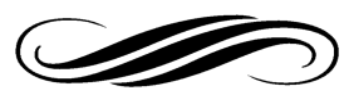

